\title{
Vaginal Delivery
}

National Cancer Institute

\section{Source}

National Cancer Institute. Vaginal Delivery. NCI Thesaurus. Code C81303.

Birth of the fetus through the vagina. 